\title{
THE ANTAGONISM OF CURARE: THE CARDIAC EFFECTS OF ATROPINE AND NEOSTIGMINE
}

\author{
Joel D. Gottlueb, ar.D., ANo RobiRt B. Sweet, M.D. ${ }^{*}$
}

Although CURARE has come into wide use as a relaxant in conjunction with general anaesthesia, the problem of reversing its effects has not yet been solved. There is no doubt that neostigmine is antagonistic to curare and can reverse nondepolarizing neuromuscular blockade, ${ }^{1}$ but many anaesthesiologists would agree with Foldes ${ }^{2}$ that the safest course is to assist respiration if the patient's ventilation is inadequate at the conclusion of operation. Neostigmine bromide is used only with hesitancy and in small doses, if it is used at all.

We have, therefore, attempted to study the effects of relatively large doses of atropine and neostigmine upon the heart to determine whether this unquestionably useful technique may be safely employed.

\section{HisTORY}

The first reports of death associated with the administration of atropine and neostigmine appeared in the British literature in 1949.,4,5 In these three cases, cardiovascular collapse followed very shortly after the administration of neostigmine and atropine. The doses were $2.5 \mathrm{mg}$. neostigmine with $0.65 \mathrm{mg}$. atropine, $^{3} 2.0 \mathrm{mg}$. neostigmine with $0.65 \mathrm{mg}$. atropine, ${ }^{4}$ and, in a 3-kg. infant, $0.25 \mathrm{mg}$. neostigmine with $0.22 \mathrm{mg}$. atropine. ${ }^{5}$ In each case the two drugs were given simultaneously.

Shortly afterward, Bain and Broadbent ${ }^{6}$ postulated the mechanism of these deaths, pointing out that atropine can cause an increase in cardiac vagal tone centrally before it causes a decrease in tone peripherally. Thus, they said, instead of preventing neostigmine's undesirable effects, atropine may potentiate them. Moreover, they felt atropine would have.little effect on a neostigmine-induced bradycardia because "the peripheral anti-acetylcholine effects of atropine take some 20 to 30 minutes to become fully established." The authors admitted, however, that they were speaking of subcutaneous doses of atropine and had "no experience" with the effects of intravenous administration.

Since neostigmine has been implicated in other cases of cardiac arrest, ${ }^{7,8}$ it is easy to see how the current distrust of this agent came about. There is a considerable body of evidence, on the other hand, which makes this view hard for some investigators to accept. In the first place, studies involving the intravenous administration of atropine in man show that there is no central vagal stimulating effect; the pulse rate rises and reaches its maximum in 3 to 5 minutes. ${ }^{9}$ Hunter $^{10}$ found that when atropine and neostigmine were administered together intravenously the pulse rate rose to a peak within 5 minutes and then fell slowly, the greatest

\footnotetext{
"Department of Anesthesiology, The University of Michigan Medical School, Ann Arbor, Michigan, U S.A.
} 
bradycardia occurring 10 minutes after injection. He felt that the neostigmine acted more slowly than the atropine. It is also worth noting that in Hunter's study none of the 25 unanaesthetized patients who received $2.5 \mathrm{mg}$. neostigmine and $1.3 \mathrm{mg}$. atropine showed any cardiac irregularity.

In some studies, atropine itself has appeared to be responsible for the cardiac disturbances noted with this combination of drugs. Pooler has reported a case ${ }^{11}$ in which $0.3 \mathrm{mg}$. atropine produced severe arrhythmia and cyanosis; after the pulse returned to normal, $2.0 \mathrm{mg}$. neostigmine was given "without incident:" He points out that none of the deaths associated with neostigmine were preceded by bradycardia, and he advances the view that the cardiac arrests were due to atropine administered in the presence of $\mathrm{CO}_{2}$ retention. This view is supported by the work of Johnstone, ${ }^{12}$ who has shown that atropine given to patients with elevated $p \mathrm{CO}_{2}$ produces ventricular arrhythmias in less than 30 seconds. In 15 patients so treated, 5 developed bigeminy and 10 multifocal ventricular tachycardia. In two other studies, patients under cyclopropane anaesthesia were found to develop a variety of arrhythmias when atropine was administered. ${ }^{13,14}$

Such conflicting evidence can yield no definite conclusion regarding the effect of atropine and neostigmine on the heart of an anaesthetized subject. To clarify this point we have investigated the changes in cardiac rate and rhythm that occur following the administration of atropine and neostigmine in conjunction with a variety of anaesthetic agents.

\section{Details of the Study}

For our study series, surgical patients were selected who did not have asthma or any kind of active heart disease or any history of cardiac conduction defect or arrhythmia, and who were neither very young nor very elderly. Thus the series eventually comprised 82 patients ranging from 12 to 68 years of age and from 90 to 250 pounds in weight. On the basis of their clinical condition they were classified according to surgical risk, in grades 1,2 , and 3. The anaesthetic agents used were nitrous oxide and oxygen, either alone or supplemented by ether, cyclopropane, or halothane, and d-tubocurarine in doses ranging from 15 to $120 \mathrm{mg}$. (the size of the dose having no effect on the variables measured).

After the induction of anaesthesia, base-line E.K.G. recordings from leads 1 and 2 were taken for 1 minute every 15 to 20 minutes. At the conclusion of the operation, when relax tion was no longer necessary, a continuous recording of E.K.G. leads 1 and 2 was begun and approximately 2 minutes later the neostigmine and atropine were administered, according to the following technique. If the E.K.G. tracing was not unusual or if it showed an abnormality which was constant over the 2-minute period, the patient was given $1.2 \mathrm{mg}$. of atropine sulphate intravenously. The time of the injection varied from 1 . second to 50 seconds and the interval was recorded precisely on the E.K.G. record. When the tachycardia reached its height and was no longer increasing, $2.5 \mathrm{mg}$. of neostigmine bromide was given intravenously. E.K.G. recording was continued until anaesthesia had ended or until the patient, though still anaesthetized, was moved from the operating table.

When the E.K.G. tracings were reviewed, pulse rates were determined at 15- 
second intervals, or more frequently if rapid changes were noted. Both normal and abnormal traeings were reviewed with a consultant cardiologist.

The first 10 patients in the study were also tested for tidal volume and $p \mathrm{CO}_{2}$ before and after the curare antagonists were administered. We found that $p \mathrm{CO}_{2}$ under controlled respiration ranged from 24 to $35 \mathrm{~mm}$. Hg. No effective tidal volumes were recorded before the injection of neostigmine; after the injection the values ranged from 400 to 700 c.c.

\section{ResUlts}

Of the 82 patients studied, arrhythmias occurred in 19 as a result of our experimental procedure (Table I). It is of great importance to note that all arrhythmias

TABLE I

Types of Arrhythmias |Observed

\begin{tabular}{|c|c|c|c|c|c|}
\hline Anaesthesia & $\begin{array}{l}\text { Number } \\
\text { of cases }\end{array}$ & $\begin{array}{l}\text { Patients } \\
\text { with } \\
\text { arrhythmias }\end{array}$ & $\begin{array}{c}A-V \\
\text { dhssociation }\end{array}$ & $\begin{array}{l}\text { Nodal } \\
\text { rhythm }\end{array}$ & Ventricular \\
\hline \multicolumn{6}{|l|}{$\begin{array}{l}\text { Nitrous } \\
\text { oxide }\end{array}$} \\
\hline $\begin{array}{l}\text { alone } \\
\text { Nitrous }\end{array}$ & 14 & 1 & 1 & 0 & 0 \\
\hline $\begin{array}{l}\text { oxide } \\
\text { and ether }\end{array}$ & 13 & 3 & 1 & 1 & 2. \\
\hline $\begin{array}{l}\text { Nitrous } \\
\quad \text { oxide and } \\
\text { cyclopropane } \\
\text { Nitrous }\end{array}$ & 24 & 10 & 6 & 4 & 5 \\
\hline $\begin{array}{l}\text { oxide and } \\
\text { fluothane }\end{array}$ & 31 & 5 & 2 & 2 & 1 \\
\hline Totals & 82 & 19 & 10 & 7 & 8 \\
\hline
\end{tabular}

developed following the administration of atropine; none followed the administration of neostigmine. No patient who was without an arrhythmia before receiving neostigmine subsequently developed any changes except bradycardia.

Bradycardia, evidenced by a pulse rate of 50 or lower, appeared in only $\backslash 4$ patients, all of whom showed normal pulse rates at the conclusion of the tracing. One of these patients had a resting pulse rate of less than 50 before the induction of anaesthesia, and although the rate fell to 43 ten minutes after the administration of neostigmine, there was no change in blood pressure, and at the conclusion of the tracing the pulse rate was 65 .

By far the most common arrhythmia we observed, occurring in 10 of the 19 patients, was atrioventricular dissociation (Fig. $\mathbb{l}$ ). This phenomenon occurs when the atria and ventricles begin beating independently of one another, and is diagnosed by variation in the PR interval. The ventricular rates do not fall below the atrial rates, however, as is the case in true heart block. No clinical significance is attached to this disturbance.

The phenomenon of nodal rhythm was noted in 7 patients. In this condition, the atrioventricular node takes over as the pacemaker for the heart when the sino- 


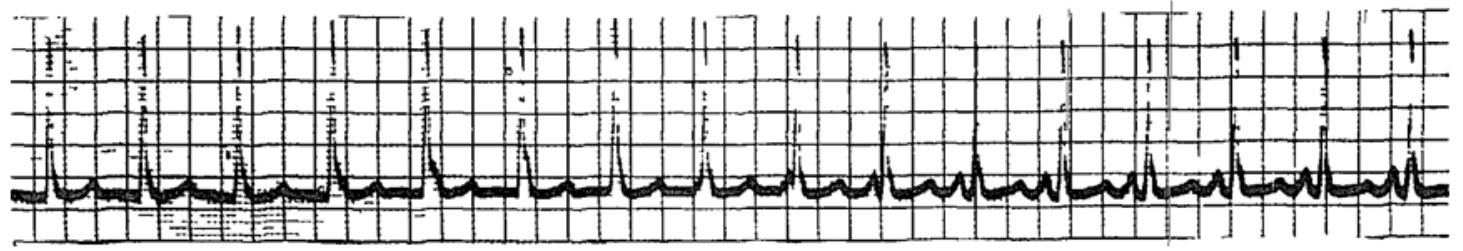

Figure 1. Atrioventricular dissociation. The atria and ventricles are firing independently. Note the P-wave, which moves from behind the QRS complex to its normal position. Tracing taken 1 mmute 30 seconds after administration of atropine.

atrial node's rate falls below the intrinsic rate of the A-V node. It is diagnosed by an abnormal or inverted configuration of the P-wave (Fig. 2). This arrhythmia also is considered to be clinically unimportant.

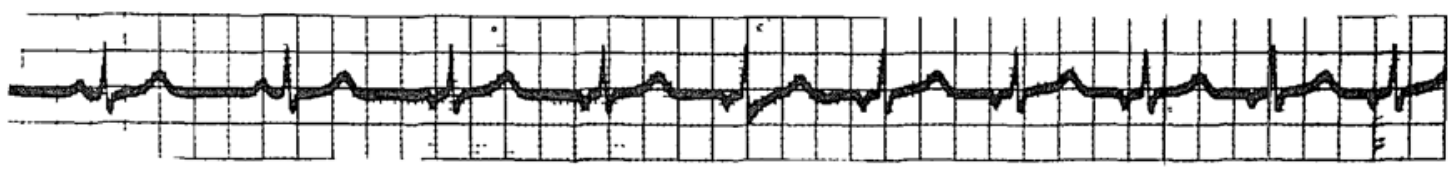

Figure 2 Nodal rhythm Note how the P-wave suddenly mverts after two cycles, indicating that the impulses are now ongunating in the atrioventricular node. Taken 45 seconds after atropine administration

Ventricular arrhythmias occurred in 8 cases, including ectopic systoles in 4, bigeminy in 5 , and multufocal tachycardia in 1 . As disturbances in ventricular 1 hythm are considerably more serious than supraventricular arrhythmias, these 8 cases were analysed in more detail, with the following results:

In 2 cases in which the patients had received ethyl ether, ventricular extrasystoles were manifested throughout the course of anaesthesia at various times, but not consistently. Following the administration of atropine both patients developed increased numbers of ventricular extrasystoles, but no blood pressure change or other untoward effect was observed.

Four of these patients developed extrasystoles or bigeminy with supraventricular rhythm disturbances. One of these is illustrated in Figure 3. In this case,



FIGURE 3. Bigeminy. Note the emergence of the ventricular ectopic focus in the first few cycles. This tracing was taken less than 20 seconds after atropine administration.

bigeminy appeared 2 minutes and 50 seconds after the administration of atropine, and persisted for less than a minute. During the next 20 minutes there were frequent brief intervals of bigeminy, A-V dissociation, and nodal rhythm, as well as an irregular R-R interval. Twenty-one minutes after the administration of neostigmine, normal sinus rhythm was established and no further abnormalities appeared. The other 3 cases in this group showed similar but shorter episodes of bigeminy or multiple extrasystoles. The anåesthetist could detect an irregular 
pulse but noted no change in the patients' clinical condition. All 4 of these patients had received cyclopropane.

In another case in which cyclopropane was used, multifocal ventricular tachycardia appeared 45 seconds after the administration of atropine (Fig. 4), occa-


Figure 4. Multifocal ventricular tachycardia. This patient had received cyclopropane and oxygen First strip 1 minute prior to $1.2 \mathrm{mg}$. atropine administration intravenously Second strip. 30 seconds after atropine admmistration. Third strip 1 minute 10 seconds after the atropme administration. Fourth strip 2 minutes 30 seconds after atropine administration Fifth strip 6 minutes 20 seconds after atropine administration Throughout the period of severe arrhythmia, there was no change in blood pressure

sional extrasystoles had been noted before the atropme was administered The multifocal tachycardia persisted, without E.K.G. evidence of atrial actin itv for 9 minutes and 15 seconds. Within the next minute and a half, howeres, normal sinus rhythm developed with only. occasional extrasystoles. The blood piessure remained at its normal level of $120 / 70$ throughout this episode and the patient suffered no ill-effects.

The last patient in this group developed bigeminy 55 seconds after the administration of atropine, and this was accompanied by an elevation in blood pressure 
from $110 / 70$ to $220 / 130$. The patient had received halothane, and also $50 \mathrm{mg}$. of methedrine intravenously because of hypotension (90/60), 50 minutes before the experiment was begun. The pulse rate, 54 before the atropine was given, rose to 83 within 25 seconds and to 110 within 40 seconds, at which point the bigeminy began. Normal sinus rhythm lasting for 10 seconds occurred 1 minute and 15 seconds after the atropine administration; after another 50 seconds of bigeminy, normal sinus rhythm became established. The blood pressure fell gradually so that 22 minutes after the atropine administration it was $130 / 90$. The patient's pulse rate at this time was 55 and he was awake. There were apparently no illeffects from the episode of hypertension.

Two other points deserve mention. First, in no case did we observe any slowing of the pulse following the administration of atropine. This is true for every beat of the heart recorded after the administration of atropine; there was no shortening of the R-R interval at any time after the adminisitration of this drug. Second, all patients in this study who developed arrhythmias received the intravenous atropine in time periods of less than 5 seconds. Of the patients who did not devel $\phi p$ arrhythmias during the administration of the drugs, approximately one-half received their atropine in less than 5 seconds.

\section{Discussion}

On the basis of our results we feel that the antagonism of curare by means of atropine and neostigmine is a safe procedure. We observed no arrhythmia of any sort other than the expected bradycardia following the unusually large doses of neostigmine employed. Indeed, the bradycardia never affected the course of the anaesthesia, nor did it change the patient's blood pressure or clinical condition.

In our study, the arrhythmias produced by the administration of large doses of atropine were in most cases clinically insignificant. All of the arrhythmias were noted to follow very rapid injection of the atropine. In an actual clinical situation it is unlikely that one would inject as much as $1.2 \mathrm{mg}$. of atropine in a space of less than 5 seconds. When smaller doses are used and are injected more slowly, this technique would seem to be quite safe. The types of arrhythmias associated with the various anaesthetic agents are also worthy of note.

In two recent studies ${ }^{14,15}$ arrhythmias of the same type we encountered produced by atropine have been observed during cyclopropane 'and halothane anaesthesia. Jones et al. concluded from their results that the various anaesthetic agents, especially cyclopropane and halothane, produce changes in vagal tone and thus can proce an altered response to the administration of atropine. ${ }^{15}$ Analysis of our results, however, suggests another possible explanation of the cardiac responses to atropine. We observed arrhythmias ranging all the way from supraventricular to ventricular patterns. It would seem unlikely that alteration in vagal tone alone can account for the latter types of rhythm. In addition, the cardiac response to atropine that we observed is almost entirely related to the time of administration of the drug. So it may be that while a small dose of atropine produces the expected vagolytic response at the sino-atrial node, larger doses or those more rapidly administered may affect cardiac conduction at other levels than the vagal endings. The fact that arrhythmias are more readily pro- 
duced with halothane and cyclopropane seems to be a reflection of the effects of these drugs themselves upon myocardial conduction. Even with halothane and cyclopropane, however, we would emphasize again that the slow administration of large doses of atropine produced no arrhythmia.

The value of this technique must, of course, be judged individually for each patient. Judiciously employed, atropine and neostigmine can safely add flexibility to the technique of muscle relaxation.

\section{SUMMARY}

In a series of 82 selected surgical cases, continuous E.K.G. tracings were recorded during the administration of atropine and neostigmine for the reversal of curare-induced neuromuscular blockade. The drugs were administered intravenously and at separate times at the close of the surgical operations, during which various anaesthetic agents had been used.

Analysis of the E.K.G. tracings showed that arrhythmias occurred in 19 cases, and that in most instances the type of arrhythmia was not clinically significant. No arrhythmia was observed following the administration of neostigmine, and none following atropine when the injection time for this drug was greater than 5 seconds. It is suggested that cardiac response to atropine may be related almost entirely to the size of the dose that first reaches the heart; large or rapidly injected doses may affect cardiac conduction at other levels in addition to vagal endings.

It is concluded that neostigmine and atropine are safe to use for the reversal of the effects of curare.

\section{RÉSUMÉ}

Bien que la néostigmine soit efficace pour antagoniser le blocage neuromusculaire produit par le curare, il est arrivé qu'on lui ait attribué l'apparition d'une arythmie cardiaque. C'est pour cette raison que nous avons étudié attentivement les changements électrocardiographiques produits par l'administration intraveineuse de $1.2 \mathrm{mg}$. d'atropine et de $2.5 \mathrm{mg}$. de néostigmine chez 82 malades robustes pour antagoniser l'effet de curare. Toutes les arythmies, à l'exception de quatre cas de bradycardie, sont survenues à la suite de l'injection intraveineuse d'atropine. Nous avons observé ces arythmies dont une dissociation auriculoventriculaire chez 10 malades, un rythme nodal chez sept malades, et des arythmies ventriculaires chez huit malades. Les troubles ventriculaires sont allés de systoles ectopiques chez quatre malades, de brèves périodes de bigéminisme chez cinq, à un cas de tachycardie multifocale. Toutes les arythmies ont été transitoires et n'ont laissé aucun changement de l'état clinique du malade. Toutes les arythmies sont apparues après l'injection intraveineuse très rapide (moins de cinq secondes) d'atropine. Nous en venons à la conclusion que cette façon d'antagoniser les effets du curare est de toute sécurité, à la condition d'injecter l'atropine Ientement.

\section{REFERENCES}

1. Wescott, D A. \& Bendixen, H H. Neostigmine as a Curare Antagonust. Anesthesiology 23: 3 (1962). 
2. Foldes, F. F. Muscle Relaxants in Anesthesiology, 1st ed., pp. 84-85, Springfield, Illinois: Charles C. Thomas (1957).

3. MacIntosm, R. R. Death Following Injection of Neostigmine. Brit. J. Med. 1: 852 (1949).

4. Clutron-Bæock, J. Death Following Neostigmine. Brit. J. Med. 1: 1007 (1949).

5. Hill, Marie. Death after Neostigmine Injection. Brit. J. Med, 2: 601 (1949).

6. Bain, W. A. \& Broadbent, J. L. Death Following Neostigmine. Brit. J. Med. 1: 1137 (1949).

7. Lawson。 J. J. Cardiac Arrest Following the Administration of Neostigmine. Brit. J. Anaesth. 28: 336 (1956).

8. Doughty, A. G. \& WYLIE, W. D. Antidotes to "True" Curarizing Agents. Brit. J. Anaesth. 24:66 (1952).

9. Shearer, W. M. The Effect of Atropine and Hyoscine on the Pulse Rate in Human Subjects. Anaesthesia 6: 76 (1951).

10. Hunter, A. R. The Anti-curarizing Agents. Brit. J. Med. 1: 640 (1953).

11. Poolfr, H. E. Atropine, Neostigmine, and Sudden Death. Anaesthesia 12: 198 (1957).

12. Johnstone, M. General Anesthesia and Cardiac Inhibition. Brit. Heart. J. 13: 47 (1951).

13. Jacobson, E. \& Adelitan, M. H. The Electrocardiographic Effects of Intravenous Administration of Neostigmme and Atropine during Cyclopropane Anesthesia. Anesthesiology 15: 407 (1954).

14. Colon-Yordan, E. \& Jnmnez-Velez, D. L. Effects of Intravenous Atropine and Scopolamine during Cyclopropane-Anectine Anesthesia. Anesthesiology 23: 333 (1962).

15. Jones, R. E.; Deutsch, S.; \& Tunndonf, H. Effects of Atropine on Cardiac Rhythm in Conscious and Anesthetized Man: Anesthesiology 22: 67 (1961). 